\title{
Moral Character and Social Science Research
}

\author{
JAMES MONTMARQUET
}

Part of 'common sense morality,' I think we can allow, is that there is such a thing as moral character-meaning, roughly, some disposition to make and act on appropriate moral judgments; the idea, further, would be that some persons have this disposition to a greater extent than others-and these are in general 'morally better people' than these others. Now, an important school of thought in recent moral theory-best represented in the work of Gilbert Harman and John Doris-has attempted to cast doubt on the very existence of moral character in what they claim to be its common sense or 'folk' signification. ${ }^{1}$ This 'folk concept,' according to these theorists, does not stand up to rigorous empirical test: the claim is that social science research has shown, or certainly has tended to show, that human behaviour is better explained in terms of the 'situation' one is in, rather than in terms of one's moral character-in anything like the above sense.

What is this research? Here I will merely take note of the two experiments figuring most prominently in Harman's and Doris's arguments. In Stanley Milgram's well-known research concerning 'obedience to authority,' individuals were induced to perform acts of what would have been great cruelty, subject to such situational variables as the white laboratory jackets of the authorizing (pseudophysicians). Although the extent of their seeming indifference to the sufferings of their 'victims' varied somewhat, virtually all were willing to inflict considerable pain under the circumstances of the experiment. ${ }^{2}$ In a somewhat similar experiment, Darley and Batson showed that 'Good Samaritan behaviour' was apparently sensitive

${ }^{1}$ See in this regard Gilbert Harman, 'Moral Philosophy Meets Social Psychology: Virtue Ethics and the Fundamental Attribution Error,' Proceedings of the Aristotelian Society 99 (1999), 315-31; and John Doris, 'Persons, Situations, and Virtue Ethics,' Nous 32 (1998), 504-30.

${ }^{2}$ Stanley Milgram, Stanley 'Behavioral Study of Obedience,' Fournal of Abnormal and Social Psychology 67 (1963), 371-8.

doi:10.1017/S0031819103000342

(๑2003 The Royal Institute of Philosophy

Philosophy 782003 
to one main variable, how late one was for one's assigned appointment-and not such factors as one's moral or religious views, or even whether one had recently been studying this Biblical parable. ${ }^{3}$

We may now state the Harman-Doris argument. It begins with a specification of what character traits are:

1. Character traits are 'broad based dispositions that help to explain what they are dispositions to do." ${ }^{4}$ These dispositions are supposed to manifest themselves not just in isolated, particular situations, but across a significant variety of ones.

Harman's and Doris's take, then, on the relevant research findings might be fairly expressed in these terms:

2. Empirical research indicates that situations (situational variables) are salient in explaining behaviour, not character traits in the sense of the immediately preceding.

Insofar, then, as character traits play no evident role in explaining behaviour (and insofar as for such things, 'to be is to explain behaviour') we are led to the conclusion that:

3. Character traits do not exist (are a myth of folk morality).

\section{II}

This is a provocative, not to say, maddening, view. I pay my bills quite conscientiously the first of each month. My wealthier neighbor falls further and further into debt, as he lavishes money on a number of mistresses. To be sure, if I had allowed myself to fall into precisely his 'situation', I might exhibit some greater similarity to his behaviour (if only out of despair). All the same, part of what difference of character explains, or should explain, is why I do not, or have not as yet, allowed myself to fall into anything like this situation.

But I am getting ahead of myself, for there is much preliminary work to be done-before launching any such broadside attack. To begin, then, I will explore some themes developed by two recent critics of the Harman-Doris view.

In a recent article, Joel Kupperman not surprisingly seizes on

${ }^{3}$ J. M. Darley and C. D. Batson, “"From Jerusalem to Jericho": A Study of Situational and Dispositional Variables in Helping Behavior,' Fournal of Personality and Social Psychology 27 (1973), 100-08.

${ }^{4}$ Harman, op. cit. note 1, 318; see also Doris, op. cit, note 1, 505-6. 
Harman's somewhat thin description of this alleged myth of folk psychology, the 'trait of moral character.' ${ }^{5}$ These, recall, are said to be 'broad based' rather than narrow, purely situational, dispositions. Now, to this, Kupperman responds that even if popular opinion (or 'folk psychology') adheres to such a characterization, it is not clear that considered philosophical opinion shares, or must share, this view. More particularly, he observes that deviations from a broad tendency to honesty, say, would only disqualify one as a virtuous person if 'virtue is roughly equivalent to near perfection.' ${ }^{6}$ Kupperman goes on to point out the rich strain of fallibilism in sources as diverse as Confucius and Plato.

Now, I want to maintain that, ultimately, there is something to this line of criticism. Still, it seems to me that the Kupperman's use of the issue of perfection-of whether one must attain anything like this to be a virtuous or moral person-amounts to a red herring. First, Harman's notion of character does require it to be 'cross-situational' but it is debatable how close to perfection that takes us. Certainly, there is a great difference between perfection (or near perfection) and some reasonably large variety of situations in which one might exhibit honesty. To that extent, Kupperman overstates Harman's position. In another respect, however, Kupperman understates, or insufficiently appreciates the depth, of that position. As we remarked at the outset, the common sense, 'folk psychological' account of virtues like honesty would involve such claims as the following: (a) some persons are significantly more honest than others; (b) this fact explains differences in their behaviour-most notably, differences obtaining under roughly similar conditions. It is evident that Harman believes that such traits do not exist-a claim which clearly goes well beyond the uncontroversial point that few if any human beings attain perfect honesty-or perfect virtue generally. ${ }^{7}$ Certainly, one may adhere to (a) and (b) without being committed to either of the claims Kupperman associates with Harman's picture of the folk psychology of traits. This conjunction does not imply that truly honest individuals are honest all, or

5 'The Indispensability of Character,' Philosophy 76 (2001), 239-50.

${ }^{6}$ Op. cit., note 5, 241.

${ }^{7}$ As Harman himself remarks (317): 'To have different character traits, [two people] must be disposed to act differently in the same circumstances ...' To this Harman adds, tellingly, 'as they perceive those circumstances.' As Kupperman (op. cit, note 5, 245-6) points out, however, this seriously begs the question of whether differences in how one perceives a situation would not themselves reflect differences of character. 
nearly all, the time; it allows that one can be an honest, and a good, person, while falling considerably short of perfection.

Another critic, Gopal Sreenivasan, likewise fastens on the question of how extensive (cross-situationally consistent) typical character traits actually are-but from the standpoint of a critique of the research literature. ${ }^{8}$ Does the empirical data, he asks, demonstrate a convincing absence of cross situational consistency in subjects? A genuine measure of such consistency, in the case of a trait like honesty, he contends, must supply both a standard both of what is to count as relevant 'virtue relevant behaviour' and an 'honesty eliciting situation.'

In this regard, he notes three possible areas of difficulty': (a) There is the matter of whose specification of the situation is to count. If the situation is not one in which the subject believes honesty to be the issue, does his 'dishonesty' count against his being an honest person? (b) There is the issue of the 'degrees of relevance' of a given situation to a given virtue. In an example he cites several times, one's pocketing stray change has been taken by researchers as a sign of a lack of honesty, but one's handling of 'found objects' hardly seems central to this virtue. (c) There are questions of background norms. Suppose that one acts dishonestly for what one takes to be-even for what may be judged by observers as-overriding moral reasons. Is this an indication of dishonesty?

Sreenivasan's position, in short, is that a theory of virtue requires that there be traits which are 'cross situtionally consistent across a range of behavioral measures that satisfy all three generic requirements' (p. 63)-i.e. the experimental situation must be one recognized by the subject as testing the virtue in question, must be relevant to that virtue, and must not be affected by other relevant norms. Insofar as the social science research on moral character tends not to be sensitive to these considerations, Sreenivasan concludes that it does not support the kind of radical conclusion drawn by its philosophical champions.

Since the second of Sreenivasan categories [(a)-(c)] tends to overlap with the first and the third, I shall focus on these other two. To begin, it seems to me that his point concerning morally appropriate situations for testing cross-situational consistency can hardly be gainsaid. If Aristotle is right that virtues pertain to reasons, the presence of a strong, overriding reason not to exemplify a given trait

8 'Errors About Errors: Virtue Theory and Trait Attribution,' Mind 111 (2002), 47-68.

${ }^{9}$ Op. cit., note $8,57-9$. 
in a given situation will mean that one's failure to exemplify this trait in this situation does not count against one's moral character. In fact, it may show no more than that some other virtue, in this instance, trumps the virtue under test. What is less clear is the status of Sreenivasan's first point, the question of whether experimental subjects must themselves perceive a situation as relevant to the virtue in question. Sreenivasan and Kupperman both are inclined to think that relevant situations must be ones perceived to be so by the subject. Here it is ironic that Kupperman approvingly cites John McDowell's discussion of the importance of how one sees a certain situation for whether one possesses a given virtue. ${ }^{10}$ For, if anything, McDowell's view has the opposite implication. If part of being a generous person is seeing that a given situation calls for such a virtue, it is not correct to relativize instances of a given trait to the way one happens to see a given situation. If, as in the Darley-Batson experiment, one fails to see another's being slumped in a door way, evidently in great distress, as calling for assistance, clearly this would involve a lack of appropriate virtue. Here it is hardly appropriate to conclude, simply, that the agent is being suitably virtuous, relative to his own interpretation of the situation.

\section{III}

We have been, to this point, selectively critical of Harman's critics. I now propose to explore, somewhat more fully, this questionraised in different ways by Kupperman and Sreenivasan-of the extensiveness (or 'cross-situational' nature) of moral character. In particular, I want to begin by exploring the relation between:

(1) displaying good moral character in a given situation, and

(2) displaying good character in other, significantly different types of situation.

Certainly, there are occasions, situations in which persons do act well, and are thought to exhibit 'good moral character'. ${ }^{11}$ Now one

${ }^{10}$ See his 'Virtue and Reason', The Monist 62, (1979), 331-50.

${ }^{11}$ Doris and Harman would not seem to deny this. Certainly, Harman allows (op. cit., note 1, 327-8) for an ethics in which particular moral judgments framed in terms of what act is the right one to do in that situation will exhibit 'virtue' or 'vice' depending, I gather, on the nature (or correctness) of these judgments. Thus, to judge, when the enemy charges, that I ought to stand my ground is to judge courageously (to act on that judgment, then, would presumably be to act courageously). 
thing seems evident concerning these: namely, how virtuously one has acted in a given situation depends only on one's act and motivation in that situation and not, as such, on how one would have acted in other situations-or how one would have acted in this or other situations in the past. If John has exhibited great truthfulness in $\mathrm{S}$ (he told the truth much to his own personal disadvantage), the fact that he would not tell the truth in some quite different situation $\mathrm{S}^{\prime}$ does not detract from the virtue of his act in $\mathrm{S}$.

In Kantian (deontological) and in utilitarian terms, this contrast is clear enough. So, for Kant, to act from a sense of duty will be to exhibit good moral character in a given situation, regardless of whether one acts, or tends to act, equally well in other situations, or even in that same situation if and when it recurs. Notice, too, even a sophisticated Aristotelian can-indeed must-accommodate this consideration, basically by distinguishing the moral value of an agent and the moral value of a given act of his. Thus an Aristotelian will hold that John would be a better person (agent) if he exhibited honesty across a greater variety of situations, but will also need to hold that the honesty he exhibits in this case is nonetheless, as an individual display, no worse for his tendencies in other cases. ${ }^{12}$

In fact, if Aristotle did not maintain something like this, it is hard to see how he could offer the explanation he does of character change and development. For if the evaluation of each act depended on a full description of one's tendencies, a good act of a bad person would have so little value that it could hardly explain any resulting improvement in his character. Notice, then, to hold that the character one exhibits in any given situation must be assessed mainly in terms of what has been one's character to date

12 Glenn Hartz, 'Desire and Emotion in the Virtue Tradition,' Philosophia 19 (1991), 151, has taken quite a different view, which he also associate with Aristotle. On his view, an act cannot be judged praiseworthy unless the disposition from which it follows is one the agent would typically exhibit. In this regard, he offers the case of a racist sailor who saves a drowning black man, but only as a kind of 'fluke.' It is unclear, though, just what we are to make of this case. If the point is that, in this emergency, the sailor's normally racist dispositions failed to apply, then the act is perhaps not highly praiseworthy and is something of a fluke. If, however, the sailor has on this occasion overcome his racist impulses, then his act surely is praiseworthy - as much so as the life saving act of one who harboured no such motives. My overall claim, then, is borne out. The differences between these imagined cases correspond to differences in the sailor's actual motivation in that situation, and not differences in how he would act under other circumstances. 
will yield some very strange consequences. Sydney Carton's 'far, far better thing than I have ever done' would exhibit morally worse character than the bad act (say, a selfish lie) of a generally good person. If so, it is most unclear how this act can significantly contribute, as it has, to Carton's becoming a good person, at the end of his life. In short, no coherent theory of moral improvement, or of the virtuous quality of the individual act, can allow that its moral value, or the moral qualities it exhibits, are to be weighed down by the individual's past level of performance-or even their present tendencies in other types of situation.

Two further points, though, by way of clarification. Of course, how one would act in other situations is often a key to discovering what one's actual motivation was in a given case. If John only tells the truth to members of his fraternity, presumably this says something about his underlying motivation: he tells the truth because he is speaking to a fellow fraternity member and not for any better reasons than that. Still, this is quite compatible with our earlier claim: how well one acts (including a full characterization of one's motivation) in a given case depends only on factors pertaining to that case. Second, any disposition will have some implications for other situations-actual or possible. If John has acted well in S, arguably, this will imply_what some would take to be a tautologythat he would act well in any 'relevantly similar' situation. This, however, is hardly to make his acting well in a given situation depend in some more general way on how he would act in other types of situations. (Compare if $\mathrm{x}$ dissolves under condition $\mathrm{C}$, it will dissolve under most any instantiation of $\mathrm{C}$; but whether it will dissolve under other conditions is left open.)

Here, finally, a mechanical analogy may not be out of place. How well a given product works in a given situation, or type of situation, does not depend on how well it would work in other types. If a given vest stopped an ordinary bullet, one would be pleased at its performance. The fact that it would not have stopped an armor piercing bullet does not detract from its performance here-merely from its overall utility. Now, to be sure, if these good results had been merely fortuitous, that would count against that performance-say, it had stopped the bullet by deflecting it slightly so that it lodged in one's pocket watch. But, of course, that is not a case of good performance at all, only good luck. (This is the analogue not of a good act in a given situation, but a badly intended one with fortuitous consequences.)

Now, the importance of the foregoing for the issues raised by Harman and Doris is as follows. Their claims concerning the 
'nonexistence' of moral character, as we have seen, are pitched at the level of whether individuals exhibit significant consistencies of character across differences of situation. But this, while interesting, is really incidental to the more fundamental question of whether character, and character differences, exist within situations. Even if no cross-situational links obtain, it remains an open question whether, on a given occasion, a given individual exhibited a tendency to honesty, kindness, or some other good quality. It even remains an open question-what will concern us next-whether such an exhibition might distinguish certain agents from the 'norm' for that situation. For surely the question of whether cross-situationally exceptional behaviour exists is separate from the question of whether certain individuals may be exceptional in a given situation. In fact, given that dispositions (moral or otherwise) are typically of unequal strengths, it may be expected that some will rank near the top and some near the bottom in terms of such strength.

One last point in this regard. It may be objected: 'if situational variables are salient, issues of character are thereby excluded.' 'The error here is to confuse two quite different ways in which 'situation' might be important. A situation might 'trigger' a given genuinely moral response, without our having to conceive of that response as merely situational. Hearing a speech or sermon might occasion a genuine act of generosity-not a mere act of 'obedience to the speaker's message'. By contrast, one's behaviour in a given situation might genuinely be motivated by situational variables- the earlier case of honesty merely to fraternity members.

\section{IV}

Still, we are not out of the woods yet-by no means. For the real problem for moral character raised by this research quite remainsand has nothing to do, per se, with Harman's or Doris's characterization of moral character as extensive or cross-situational. It has to do, more simply, with whether in any given case, character does make a difference. If Mary and Bob are in the same situation, the question of whether differences of character can affect their behaviour in that situation does not concern, certainly, how they would act other situations but in this one. The problem, then, raised by such cases as the Milgram and the Darley-Batson one concerns precisely that issue: whether, or the extent to which, persons in the same situation do act differently. Certainly, these experiments suggest that the differences between what we should expect of 'good' and of 
morally average or even subpar individuals in any given situation is not as great as we would have expected. I note in passing here that this reconfiguration is not purely negative. For even if the experimental situations have had the tendency to level downward our perception of how the virtuous would act, the reverse could also be true for other situations. One can easily imagine an experiment which indicated that convicted murderers shared many of the same moral sensibilities as 'normal' moral agents.

Does, then, moral character 'make a difference'-and, if so, how? I want to approach this in two ways. First, in a more limited way, in terms of how even the Milgram experiment reveals differences of character in terms of how different agents require different incentives to exhibit the same behaviour; second, in terms of the limited relevance of any such 'experiments' to the exhibition of character in ordinary life.

There is a saying — of folk morality no less-that 'every man has his price'. Roughly speaking, this means that given a sufficient incentive to vice, everyone (or certainly most anyone) would yield. Of course, this does not mean, and cannot mean, that every man has exactly the same price-in the sense that given exactly the same incentives, or even the same perceived incentive, everyone will act in the same way. Many of us have been amused by Russell's jest concerning a woman's chastity: once it is established that she would sleep with him for some amount of money, however great, all further discussion is but 'haggling over the price'. In fact, though, whether she would require ten cents or ten million dollars to sleep with him does say something about her character. And the same logic, notice, applies to Milgram type cases. Evidently, different individuals would, and did, require different degrees of urging (of incentive) to carry out their orders. While it is striking that virtually all participants eventually went along, ${ }^{13}$ this should not blind us to individual differences, for they are liable to reveal character differences which would come out under other, less artfully constrained circumstances. Again, not everyone has the same price-financially or morally.

This point, let us observe, has implications for the legal issue of entrapment (cases in which someone commits a crime upon being induced to by the authorities, e.g., in government 'sting cases'). In U.S. law, this has been seen in terms of whether the defendant already had some character 'predisposition' to commit the crime in

${ }^{13}$ Kupperman (op. cit., note 5, 243) cites the interesting case of a man who both refused to go along with the Milgram experiment then, some years later, blew the whistle on the Mylai massacre. 
question, or whether the inducement had come entirely or mainly from the authorities. ${ }^{14}$ But this should be seen as a kind of false dichotomy. For if the authorities have arranged the situation and its incentives sufficiently well, I would be in Harman's camp: it is grossly unfair to say that his conduct indicates bad character, even if he had some previous history of such vices; for perfectly honest citizens might be similarly enticed-in which case, what becomes of the claim that 'bad character' is really at fault or displayed here? Rather, the question should be whether the inducement in question was significantly less than what the 'average man' would require to commit such an offence. For if it was, and only if it was, can we begin to conclude that the fault lay in the defendant's character and not in the situation. ${ }^{15}$

One's character as revealed in any given situation, then, is a function not just of one's act (including its motivation) and that situation broadly construed, but of what incentives to act contrary to the trait in question have been present. Individuals requiring different incentives to vice in what is otherwise 'the same situation', must be construed as having, to that extent, different moral characters. If, then, a given situation tends to provoke the same reaction from most anyone, this will be significant in demonstrating the nonexistence of character-or, more correctly, the failure of character to play any potential role in explaining differences of behaviour in this situation-only after we have explored the role of differences of incentive. If, as in the Darley-Batson experiment, one's being late is a

${ }^{14}$ A good general source on this would be Paul Marcus, The Entrapment Defense (Charlottesville, Virginia.: Mitchie Co., 1995).

${ }_{15}$ Some legal scholars, Ronald Allen, Melissa Luttreel, and Anne Kreeger, 'Clarifying Entrapment,' Journal of Criminal Law and Criminology 89 (1999), 407-31, argue, more boldly and in a Harman-Doris way, that the notion of a 'predisposition' to commit a crime, as it functions in the legal debate over entrapment, is a fiction (409). But their grounds for this claim are rather weak. They point out few people, if any, would not commit a crime, given sufficient inducement (they cite, as I have, the commonplace that 'every man has his price'), then go on to assert-what I am opposing in the text-in effect that if someone could be induced to take a bribe under some possible circumstances, his character is no different from one who would accept a bribe under most any conditions. They go on to hold that it is 'market level inducements' and these alone which serve to 'usefully sort out individuals' (410): it is only when the state has offered what is above the market or real world inducement, that a claim for exoneration can be made. But, of course, the current market rate, especially for such crimes as murder, would not mark any useful moral-or, I would think, legal-distinction. 
critical variable, character differences may still be revealed most obviously in terms of how late one must be to provoke a 'not very good Samaritan' reaction. ${ }^{16}$

I turn to my final and, I think, ultimately most telling point of discussion-which concerns character differences not as exhibited in a given situation, but as they manifest themselves over the normal course of a life. To begin, then, consider how different human life would be if it were lived mainly as a succession of Milgram-type psychological experiments. I make this observation to highlight the difference between life, and character, in their normal and naturalas opposed to any such highly artificial-setting.

Perhaps the major difference in this regard concerns the role of character in determining not just what situations we find ourselves in, but in affecting in multiple ways how we orient ourselves in that situation. Recall here my earlier point concerning the unlikelihood that a basically thrifty, conscientious type would even allow himself to get into the situation of having massive, voluntarily acquired debts. In this way, even slight differences in character magnify themselves by feeding into situational differences: a person of type $\mathrm{X}$ tends to put himself in situations likely to produce $\mathrm{X}$ behaviour. To take a particularly salient example: basically honest people tend to keep themselves out of situations in which lies are required.

The issue of 'orientation' is important here as well. A generous person's generosity will most likely be revealed not in a series of isolated, unconnected acts of spontaneous generosity, but in 'projects' - longer termed enterprises in which generosity enters in on a number of different levels, ranging from over all planning to execution. Outside of these projects, the generous person may be no more so than the average person. Hence, insofar as psychological experiments catch one 'outside' of his normal projects, persistent character traits are less likely to reveal themselves here than in other situations. Some of Milgram's subjects may have exhibited well above average compassion in their regular projects-yet in a situation in

${ }^{16}$ Notice, too, as incentives to vice increase, Sreenivasan's third category becomes relevant: one may now seen one's behaviour under the heading of new virtues. If a university administrator admits the dull-witted son of a major contributor, is this a sign of dishonesty and a lack of integrity, or of his commitment to educational goals? 
which they have not oriented themselves with respect to generosity, they may well display no more of this quality than the average. ${ }^{17}$

This is related, then, to the first of Sreenivasan's criteria: whether the subject sees the situation as calling for the character trait in question. While I disagree that virtue is strictly relative to this perception (again, there are many cases in which one claiming to have a certain virtue does not but should see a given quality as called for)—it remains true that an exclusive reliance on experimental situations abstracted from one's normal projects and the kind of orientation they involve, is not a very good way of estimating character.

Still a further difference would be that psychological experiments end. In normal life, differences of character often manifest themselves in one's follow up behaviour. Think of all the different ways in which Milgram's subjects might react upon being told what was actually going on-do these not manifest differences of character?

In short, part of the common sense, Aristotelian framework in which character plays a distinctive role has to do with the distinctive, continuing features of human life; features which are singularly ill-adapted to psychological experiments of the Milgram sort. These experiments, I concede, do tell us something, but not nearly as much, I think, as Harman and Doris make out. Insofar as one's life is an integrated, somewhat coherent series of active, relatively autonomous attempts to achieve our various ends (ends partly determined and partly constrained by character), the role of character in human life is not well measured in situations in which we are basically passive creatures, whose larger plans and purposes are 'on hold', as we respond to a situation of someone's else's construction.

Here, however, the following objection may suggest itself. 'The

${ }^{17}$ This consideration applies to Doris's first case in point (op. cit., note 1, 504), an experiment of Isen and Levin in which subjects were far more likely to engage in altruistic behavior-helping someone pick up papers blowing about in the ground-after having their dime returned to them in a phone booth. Here, again, a spontaneous outcome is shown to be highly sensitive to a chance and what would have seemed almost an extraneous situational variable. But this not to say that these individuals did not differ markedly in the degree of altruism their lives might have demonstrated. Some persons who are very altruistic in their planned, concerted efforts may be perfectly 'normal' in their spontaneous reactions. In fact, one might even expect an Andrew Carnegie, involved in some great long-term philanthropic enterprise, to be relatively insensitive to opportunities for spontaneous generosity. 
previous direction of your treatment of moral character had a highly 'particularist' or, one could even say, 'situationalist' bent to it. Character existed, and needed to be assessed, in situation. Now, though, you stress the 'cross situational' nature of character, its role tying our responses together, and achieving practical and moral coherence, across differences of situation. But does this not contradict, or stand certainly in very great tension with respect to, your earlier taken position?'

There is no contradiction, nor really a 'tension' here. Take, for instance, our parent claim that how well one acts in a given situation does not depend on how well one would have acted in some different type of situation. This is eminently consistent with such points as that character helps to determine what situations one is liable to be in. For what the first point implies is simply that our assessments of such 'situational selections' should be assessed, in terms of their quality of character, independently of how one would act in other situations. So, for instance, if it lies in my character to avoid situations in which I might be unable to pay my bills, this means that I will typically take, or avoid, certain acts. Insofar as I accomplish, my character may be positively evaluated for such accomplishments-in the situations in which they are carried out. Again, though, whether I would act similarly in other situations, while it says much about me as an agent, is not strictly relevant to how well I acted in that situation.

The difference here might be put as follows. The particularist strain in what I have to say is ethical and even ontological. Character exists, or manifests itself, in situations and must be assessed accordingly. But the larger goals or purposes of one's situational activity are typically not comprehensible solely by reference to that situation, but extend into the future and back into the past. To revert to our earlier mechanical analogy, how well something is working needs to be assessed in terms of the particular situation in which it is functioning; but that is not to say that its larger purpose is comprehensible solely, or mainly, in terms of that situation. The larger purpose of bullet proof vests is not merely to stop bullets but to save lives.

\section{VI}

Summarizing, then, the fundamental flaw, as I see it, in the view of such critics of 'folk psychology' as Harman and the psychologists, Nisbett and $\operatorname{Ross}^{18}$ is this. They infer from the absence of

${ }^{18}$ R. E. Nisbett and L. Ross, Human Inference: Strategies and Shortcomings of Social Yudgment. (Englewood Cliffs, N.J.: Prentice-Hall, 1980). 


\section{James Montmarquet}

confirming experimental evidence that the folk psychological notion is false. But why not infer that experiments are simply a poor way of revealing character? Evidently, their view is that experiments, being 'scientific', must have a greater initial credence than our common, unscientific views in this regard. Harman claims that relying on folk psychology is like relying on 'folk physics'. But this is a strained analogy-given the marked success of scientific physics, the marked lack of success of folk physics, the uncertain state of social scientific knowledge, and the quite sophisticated state of our knowledge within what Wilfrid Sellars called the 'manifest image'. ${ }^{19}$ Aristotle's and Tolstoy's systems of nature may have been bypassed by the progress of physics, but has contemporary social science rendered their understanding of human behaviour similarly 'obsolete'?

Tennessee State University

19 'Philosophy and the Scientific Image of Man', in Science, Perception, and Reality (London: Routledge and Kegan Paul, 1963). 